\title{
Comparative Study of Fatigue Damage Models Using Different Number of Classes Combined with the Rainflow Method
}

\author{
Sahnoun Zengah \\ Mascara University \\ Algeria \\ zengahsahnoun@yahoo.fr
}

\author{
Abdelkrim Aid \\ Mascara University \\ Algeria \\ aid_abdelkrim@yahoo.com
}

\author{
Mohamed Benguediab \\ Djillali Liabes University \\ of Sidi Bel Abbes, Algeria \\ benguediab_m@yahoo.fr
}

\begin{abstract}
Fatigue damage increases with applied load cycles in a cumulative manner. Fatigue damage models play a key role in life prediction of components and structures subjected to random loading. The aim of this paper is the examination of the performance of the "Damaged Stress Model", proposed and validated, against other fatigue models under random loading before and after reconstruction of the load histories. To achieve this objective, some linear and nonlinear models proposed for fatigue life estimation and a batch of specimens made of 6082T6 aluminum alloy is subjected to random loading. The damage was cumulated by Miner's rule, Damaged Stress Model (DSM), Henry model and Unified Theory (UT) and random cycles were counted with a rain-flow algorithm. Experimental data on highcycle fatigue by complex loading histories with different mean and amplitude stress values are analyzed for life calculation and model predictions are compared.
\end{abstract}

Keywords- damage models; damaged stress model; performance; random loading

\section{INTRODUCTION}

Methods for fatigue-life assessment can be divided into two groups. One of them includes algorithms based on numerical methods of cycle counting [1-6] and the other group uses spectral analysis of stochastic processes [3, 5]. In the first group, the material loading is represented by stress or strain histories, and in the second group it is represented by their frequency characteristics, i.e., power spectral density functions [6].

Engineering structures are often subjected to complex loads that undergo cyclic changes in time. They can be regular, when amplitudes and cycle shapes remain constant or irregular with stepwise changes in amplitudes or cycle shapes (so-called block loading), as well as stochastic, when amplitudes or cycle shapes vary in a random manner. Cumulative fatigue damage is an old, but not yet resolved problem. In general, cumulative fatigue damage theories can be classified into two categories: (1) linear damage cumulative theories and (2) nonlinear damage cumulative theories.

More than eighty years ago, in order to predict residual life, Palmgren suggested the concept which was later popularised by Miner [7] and is known as linear Miner rule expressed in a mathematical form as:

$$
D=\sum_{i=1}^{n} \frac{n_{i}}{N_{R i}}=\sum_{i=1}^{n} \beta_{i}
$$

where $\mathrm{n}_{\mathrm{i}}$ is the number of cycles at a given stress amplitude, $N_{R i}$ is the number of cycles failure at the same stress amplitude and $D$ is the damage variable (it is equal to 1 in correspondence of exhausted life).

Many researchers have tried to modify Miner's rule, but, due to its intrinsic deficiencies, no matter which version is used, life prediction based on this rule is often unsatisfactory [8]. Richart and Newmark [31] introduced the concept of the damage curve to overcome the deficiencies associated with the linear damage rule. Upon this concept and the results of load sequence experiments, Marco and Starky [9] proposed the first nonlinear load dependent damage theory, represented by a power law:

$$
D=\sum_{i=1}^{n}\left(\beta_{i}\right)^{x_{i}}
$$

where $x_{i}$ is a variable quantity related to the loading level.

This rule allows taking correctly into account the effects of different loading sequences. Experience has shown that only in some case and for some materials this law, and the other theories derived from it, have shown good agreement with experimental results. Moreover, the involved coefficients $x_{i}$ have to be calculated for each different load and load condition limiting their use in engineering applications [10].

Damage theories based on endurance limit reduction have also been developed. Kommers and Bennett [32,11] further investigated the effect of fatigue pre-stressing on endurance properties using a two level step loading method. Their experimental results suggested that the reduction in endurance strength could be used as a damage measure.

Henry [12] is the first who correlated the damage parameter to life fraction. This model does not take into account the load interaction effects. With some assumptions [38], Henry showed that damage $D$ stored by a test bar may be defined as the relative variation of the fatigue limit: 


$$
D=\frac{\sigma_{D}-\sigma_{D}^{\prime}}{\sigma_{D}}
$$

Expression of damage proposed by Henry is written as:

$$
D=\frac{\frac{n}{N}}{1+\frac{\sigma_{D}\left(1-\frac{n}{N}\right)}{\sigma-\sigma_{D}}}
$$

$$
\text { Or, if we set } \gamma=\frac{\sigma-\sigma_{D}}{\sigma_{D}}=\text { stress ration and } \beta=\frac{n}{N}
$$

$$
D=\frac{\beta}{1+\frac{1}{\gamma}(1-\beta)}
$$

where $n$ is the applied number of cycles and $\mathrm{N}$ the number of cycles to crack initiation in the Wöhler curve.

It is noted that for $\sigma_{D}^{\prime}=0$, we have $D=1$ and that, when $\sigma \rightarrow \sigma_{D}, \gamma \rightarrow 0$ and $D \rightarrow 0$.

Early theories accounting for load interaction effects were developed by Corten-Dolon [13] and Freudenthal [14, 15]. Both theories are based on the modification of the S-N diagram.

Bui-Quoc, [16, 17] developed a theory named Unified Theory that used the concept of Henry [12] and Gatts [18] combined with some parameters of Shanley [19] and Valluri [20] theories. Unified theory is based on the representation of the damage by reducing the endurance limit of the material; it is formulated as a relation of the type:

$$
\left(\frac{\sigma_{D}}{\sigma_{D 0}}\right)=\left(\frac{R_{m}}{R_{m 0}}\right)^{m}
$$

The endurance limit decrease, according to the number of cycles, following the form:

$$
\frac{d\left(\frac{\sigma_{D}}{\sigma_{D 0}}\right)}{d n}=-\frac{1}{a}\left(\frac{\sigma_{D}}{\sigma_{D 0}}\right)^{b}\left(\frac{\sigma}{\sigma_{D 0}}-\frac{\sigma_{D}}{\sigma_{D 0}}\right)^{2}
$$

where $\mathrm{a}$ and $\mathrm{b}$ are constants of the material.

The damage is suggested by Bui-Quoc [21] as

$$
\begin{aligned}
& D=\frac{\beta^{s}}{\beta^{s}+\left(1-\beta^{s}\right) \frac{\lambda_{2}-\left(\lambda_{2} / \lambda_{f}\right)^{8}}{\lambda_{2}-1}} \\
& \lambda_{f}=\frac{\sigma_{u}}{\sigma_{D}} ; \quad \lambda_{2}=\frac{\sigma}{\sigma_{D}}
\end{aligned}
$$

where $s$ is a parameter which is determined by the loading condition.

A new nonlinear approach, based on damage mechanics, has been proposed with the original concepts developed by Kachanov [39] and Rabotnov [40]. Lemaitre [22, 23] applied these principles to formulate a nonlinear damage evolution equation in the form:

$$
\delta D=\left[1-(1-D)^{\beta_{c}+1}\right]^{\alpha}\left[\frac{\sigma_{a}}{M_{0}(1-D)}\right]^{\beta_{c}} . \delta n
$$

Where $\beta_{c}, M_{0}$ and $\alpha$ are coefficients of the Chaboche model. $\beta_{c}$ and $M_{0}$ depend on material and $\sigma_{a}=\sigma_{\max }-\sigma_{m}\left(\sigma_{\max }\right.$ and $\sigma_{m}$ are respectively the maximum and the mean stress of cycle); the exponent $\alpha$ depends on the loading $\left(\sigma_{\max } ; \sigma_{m}\right)$ which results in non-separability between damage and loading.

Recently, a model was suggested and validated by Mesmacque [24] and Aid [25, 26, 27, 33, 41] that does not require too many properties of the material and it takes into account the loading history. This model is connected cycle by cycle with Wohler's curve. The damage is calculated with the relation

$$
D_{i}=\frac{\sigma_{(i) d}-\sigma_{i}}{\sigma_{u}-\sigma_{i}}
$$

where $\sigma_{(i) d}$ is the damaged stress; $\sigma_{i}$ is the applied stress, and $\sigma_{u}$ is the ultimate stress.

The indicator of damage at level $i$ is calculated from (9), then it is transposed to the level $i+1$ by the relation:

$$
D_{i}=\frac{\sigma_{\text {equiv }}-\sigma_{i+1}}{\sigma_{u}-\sigma_{i+1}}
$$

Where $\sigma_{\text {equiv }}$ is the equivalent stress of damage at the level $i+1$ and $\sigma_{i+1}$ is stress at the level $i+1$. For more details refer to [25-27].

The experimental observations highlighted that when a positive average stress, $\sigma_{m}$, is superposed on the cyclic loading of amplitude the life of the specimens decreases. The inverse effect is observed in the presence of average stress of compression [42].

In order to take into account this phenomenon, complementary tests can be carried out in order to establish Haigh's diagram, for lifetime fixed at $N_{R}$, the alternate equivalent stress $\sigma_{a e q}$ according to the characteristics $\left(\sigma_{a}, \sigma_{m}\right)$ of the cycle. This returns in fact to modify the curve of Wöhler for each cycle with $\sigma_{m} \neq 0$.

The real loadings are often more complex. Estimation of fatigue life of a material subjected to random loading needs suitable calculation algorithms. In such algorithms, cycle counting [28] according to a given method (for example, the 
Rain Flow method) and damage accumulation according to the assumed hypothesis are the main operations.

In this investigation, Miner's rule, Henry Model, Unified Theory and Damaged Stress Model are retained to damage accumulation and lifetime prediction of components subjected under random loading.

\section{MATERIAL AND METHOD}

\section{A. Material, shape of the specimens and loading conditions}

The experiments were conducted on the aluminum alloy 6082-T6, its chemical composition and principal mechanical properties are respectively presented in Table I and Table II. The tests were carried out on planar specimens, which were cut from a plate with a $8 \mathrm{~mm}$ thick (see Figure 1).

The fatigue tests were carried out using a $100 \mathrm{kN}$ capacity Instron Servo-hydraulic machine 8500 for tests of planar specimens made of aluminum alloy $6082 \mathrm{~T} 6$ under uniaxial tension-compression. While testing, the level of sinusoidal loading amplitude was controlled at zero mean value and $30 \mathrm{~Hz}$ frequency. The experiments were carried out under uniaxial constant amplitudes for determining the Wohler's curves modeled by (12) according to ASTM standards [29]:

$$
\log (\sigma)=A-m \cdot \log \left(N_{R}\right)=6.8-0.1024 \cdot \log \left(N_{R}\right)
$$

where $N_{R}$ is the number of cycles to fracture, $\sigma$ is the stress amplitude and $m$ is the exponent of the Wohler's curve. The fatigue limit of our material at $N_{R}=2.10^{6}$ is found to be $\sigma_{f}=$ $220 \mathrm{MPa}$.

TABLE I. NOMINAL CHEMICAL COMPOSITION OF THE $6082 \mathrm{~T} 6$ ALUMINIUM ALLOY

\begin{tabular}{|c|c|c|c|c|c|c|c|c|c|}
\hline Element & $\mathrm{Si}$ & $\mathrm{Fe}$ & $\mathrm{Cu}$ & $\mathrm{Mn}$ & $\mathrm{Mg}$ & $\mathrm{Cr}$ & $\mathrm{Zn}$ & $\mathrm{Ti}$ & $\mathrm{Al}$ \\
\hline Mean \% & 0.7 & 0.24 & 0.06 & 0.9 & 0.6 & 0.02 & 0.06 & 0.02 & Rest \\
\hline
\end{tabular}

TABLE II. MECHANICAL PROPERTIES OF THE 6082T6 ALUMINUM ALLOY

\begin{tabular}{|c|c|c|c|}
\hline Sy (MPa) & UTS (MPa) & E (GPa) & A (\%) \\
\hline 347 & 370 & 73 & 12 \\
\hline
\end{tabular}

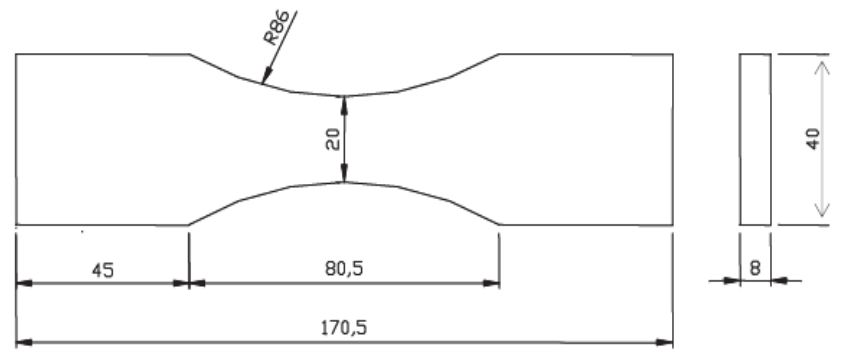

Fig. 1. Fatigue specimens-dimensions in millimeters

\section{B. Random loading}

The specimens were tested under random spectrum (original spectrum generated between -1 and +1 ), (see Figure
2), with different mean value of stress and various standard deviations (STD) values. Densities and the stress distributions for spectra, whose characteristics defined, are represented in Figures 3 and 4. Cycles were counted using the rain-flow method for numbers of classes equal to $11,20,25,32,40,50$ and 64 .

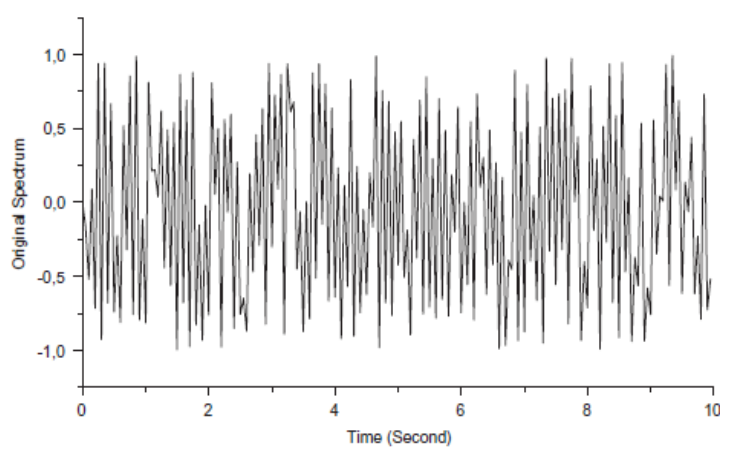

Fig. 2. Original load history.

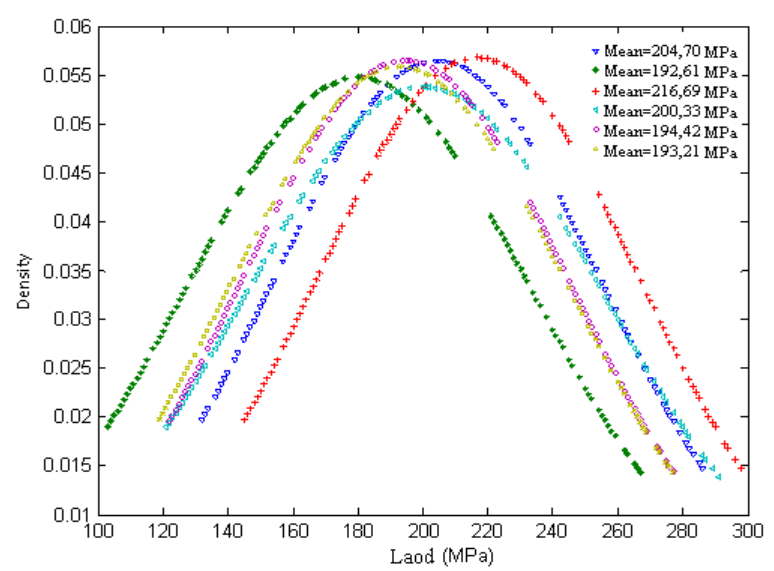

Fig. 3. Load density with constant standard deviation (STD) and different mean value.

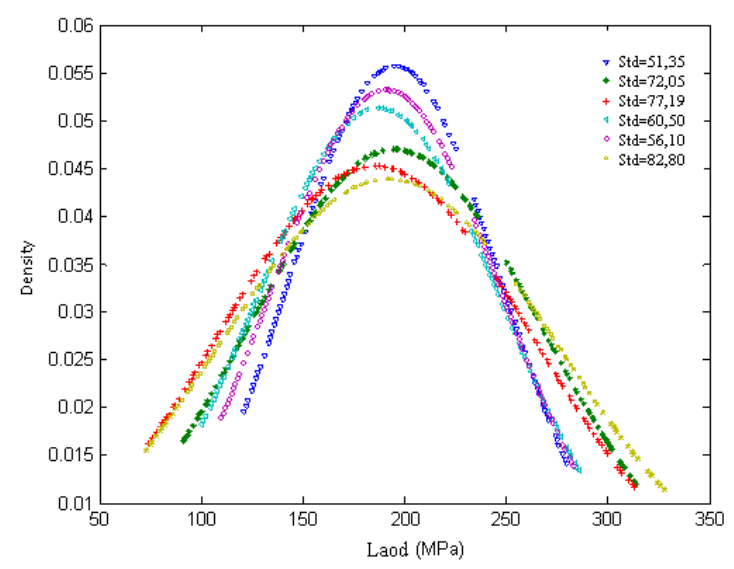

Fig. 4. 4. Load density with constant mean value and standard deviation (STD). 


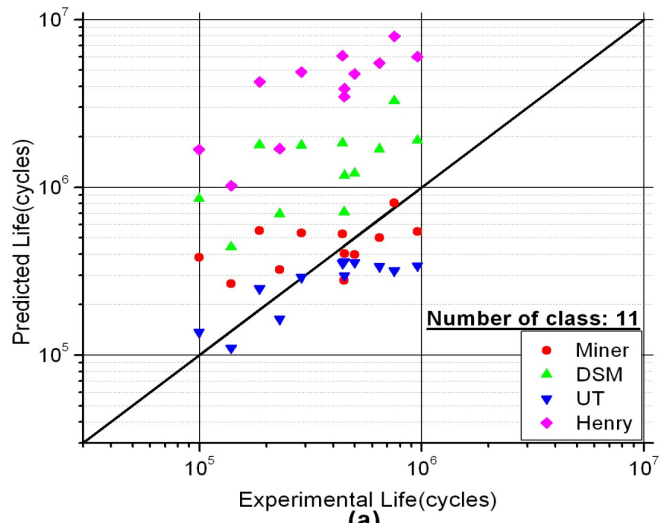

(a)

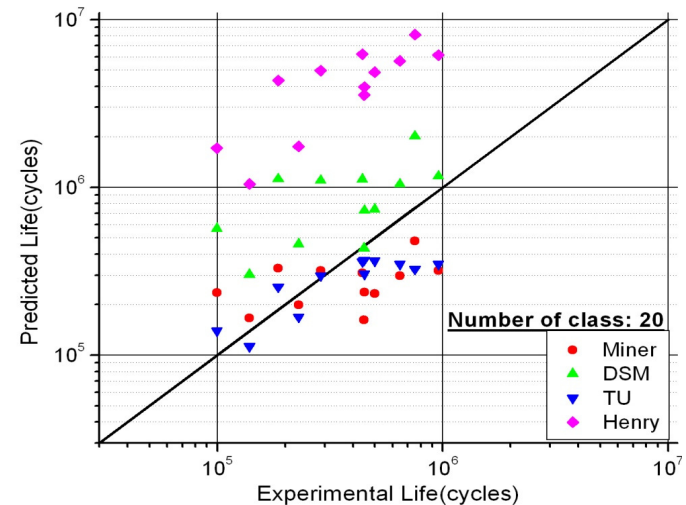

(b)

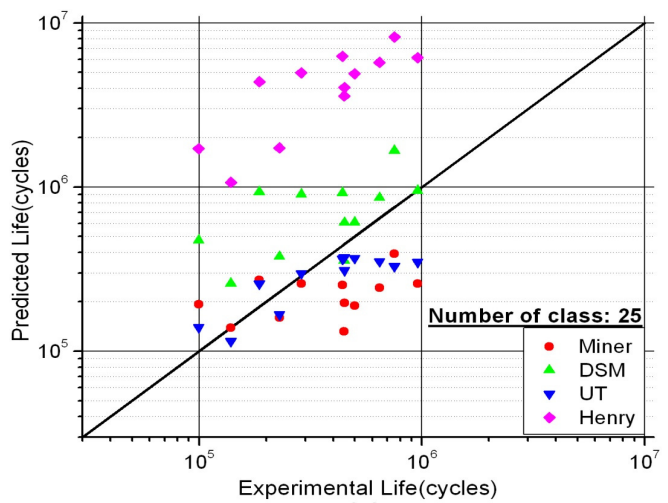

(c)

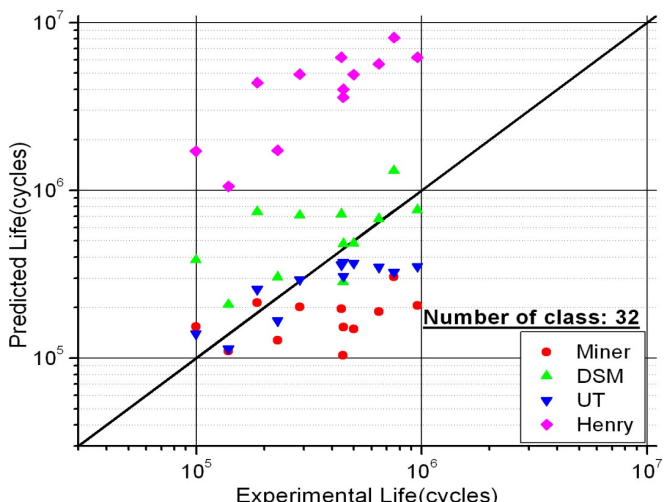

(d)

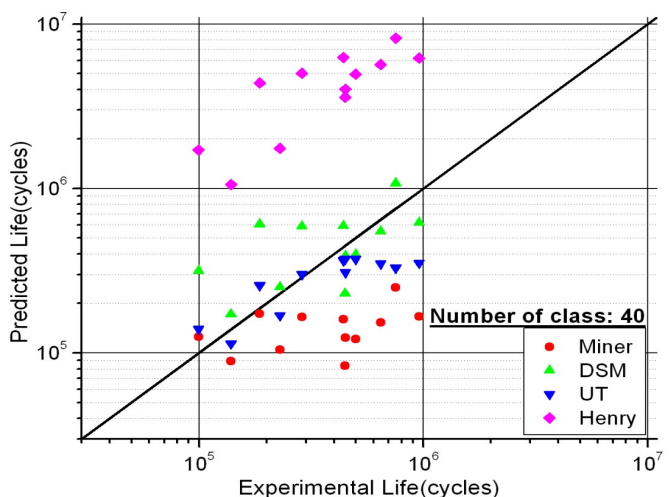

(e)

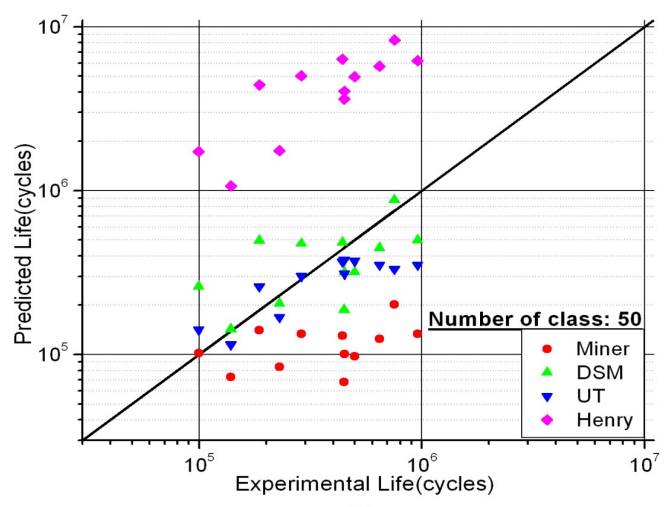

(f)

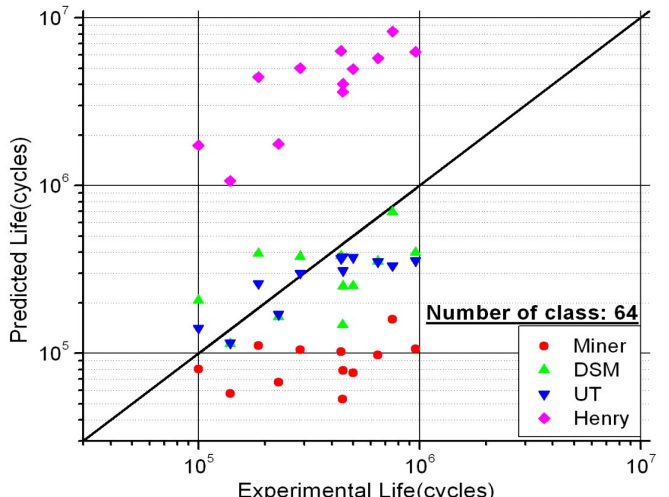

(g)

Fig. 5. Comparison between theoretical results and experimental results for different number of classes ((a) 11, (b) 20, (c) 25, (d) 32, (e) 40, (f) 50, (g) 64). 


\section{RESULTS AND DISCUSSION}

Reconstruction techniques that create the exact original history from some compact characterization have not been achieved due to complex algorithms and large storage requirements [30]. Reconstructions from statistical methods produce good results for random histories and, therefore, reconstructions based on cycle counting must be employed [43]. Hence, reproduction of histories that yield damage equivalent to the original history, without necessarily being identical to the original history, is desirable [34]. Reconstructions from simple cycle counting methods may produce histories with damage characteristics different from the original history. This problem arises from shortcomings in the cycle counting techniques [2]. Reconstructions from the rain-flow technique, however, always produce the same load cycles. Only the ordering of the cycles is different.

Life prediction and cycle counting are independent of each other. Any pairing of the two procedures will yield a life prediction because any life prediction model requires cycle information for input. Hence, fatigue life may be predicted once the cycle counting is performed. Since the rain-flow cycle counting procedure is used for load spectrum regeneration, it is also used as an input to the life prediction model, as a matter of convenience. This is desirable; however, the rain-flow method typically predicts life better than the simpler cycle counting methods [35].

The experimental results and different model's (Miner, DSM, Henry and Unified Theory) life prediction under random loading, in the above conditions and for cycles count by a rain-flow algorithm with different number of classes are compared. Comparison for a number of classes equal to 11 , 20, 25, 32, 40, 50 and 64, are shown in Figure 5.

The prediction results show the following:

\section{REFERENCES}

[1] ASTM E 1049-85, "Standard practices for cycle counting in fatigue analysis", in: Annual Book of ASTM Standards, Vol. 03, No. 01, pp. 614-620, Philadelphia, 1997

[2] N. E. Dowling, "Fatigue failure prediction for complicated stress-strain histories Journal of Materials, Vol. 7, No. 1, pp. 71-87, 1972

[3] T. Lagoda, E. Macha, A. Nieslony, "Fatigue life calculation by means of the cycle counting and spectral methods under multiaxial random loading", Fatigue \& Fracture of Engineering Materials \& Structures, Vol. 28, No. 4, pp. 409-420, 2005

[4] P. H. Wirsching, M .C. Light, "Fatigue under wide band random stresses using rainflow method", J. Struct. Division., Vol. 106, No. ST7, 15931607,1980

[5] E. Macha, T. Lagoda, A. Nieslony, D. Kardas, "Fatigue life under variable-amplitude loading according to the cycle-counting and spectral methods", Materials Science, Vol. 42, No. 3, pp. 416-425, 2006

[6] M. V. Borodii, "Life calculations for materials under irregular nonproportional loading", Strength of Materials, Vol. 39, No. 5, pp. 560565,2007

[7] M. A. Miner, "Cumulative damage in fatigue", J. Appl. Mech., Vol. 67, pp. A159-A164, 1945

[8] A. Fatemi, L. Yang, "Cumulative fatigue damage and life prediction theories: a survey of the state of the art for homogeneous materials", International Journal of Fatigue, Vol. 20, No. 1, pp. 9-34, 1998

[9] S. M. Marco, W. L. Starkey, "A concept of fatigue damage”, Trans. ASME, Vol. 76, No. 4, pp. 627-632, 1945
- Both Unified Theory and Henry models are not affected by the variation of the number of classes, i.e their predictions are stable and independent of the number of classes.

- Henry model predictions are far from the experimental results and its relative error of predictions is always negative, therefore this model is highly non-conservative.

- If the number of classes is equal to 11 , the DSM model is non conservative.

- If the number of classes is equal to 64, the Miner's model is conservative.

- Unified Theory predictions are in good agreement with experimental results.

- If the applied number of classes tends to a normalized number (64), models (Miner DSM) improve their predictions.

\section{CONCLUSION}

This study is conducted to show that the proposed model (DSM) is nonlinear and takes into account the loading history. The proposed model correctly follows the experimental results and takes into account the effect of loading history. It is based only on the $\mathrm{S}-\mathrm{N}$ (Wohler) curve which has to be known just for a part of the loading conditions; the unknown part can be estimated by a wide range of models. The results show that the proposed model is affected by the change of the number of classes and the predictions are improved if the number of classes tends to standards. The result obtained from the model are in good agreement with experimental results.

[10] V. Dattoma, S. Giancane, R. Nobile, F. W. Panella, "Fatigue life prediction under variable loading based on a new non-linear continuum damage mechanics model", International Journal of Fatigue, Vol. 28, No. 2, pp. 89-95, 2006

[11] J. A. Bennett, "A study of the damaging effect of fatigue stressing on X4130 steel", Proceedings, American Society for Testing and Materials., Vol. 46, pp. 693-714, 1946

[12] D. L. Henry, "A theory of fatigue damage accumulation in steel", Transactions of the ASME, Vol. 77, No. 6, pp. 913-918, 1955

[13] H. T. Corten, T. J. Dolan, "Cumulative fatigue damage", in Proceedings of the International Conference on Fatigue of Metals, Institution of Mechanical Engineering and American Society of Mechanical Engineers, pp. 235-246, 1956

[14] A. M. Freudenthal, R. A. Heller, "On stress interaction in fatigue and a cumulative damage rule", Journal of the Aero/Space Sciences, Vol. 26, No. 7, pp. 431-442, 1959

[15] A. M. Freudenthal, "Physical and statistical aspect of cumulative damage", in Colloquium on Fatigue, Stockholm, pp. 53-62, May, 1955

[16] T. Bui-Quoc, "An interaction effect consideration in cumulative damage on a mild steel under torsion loading", Proceedings of the 5th International Conference on Fracture, Pergamon Press, Vol. 5, pp. 2625 2633, 1981

[17] T. Bui-Quoc, J. Dubuc, A. Barergui, A. Biron, "Cumulative fatigue damage under strain controlled conditions", Journal of Materials, Vol. 6, No. 3, pp. 718-737, 1971

[18] R. R. Gatts, “Application of a cumulative damage concept to fatigue”, J. Fluids Eng., Vol. 83, No. 4, pp. 529-534, 1961 
[19] F. R. Shanley, A theory of fatigue based on unbonding during reversing slip, report P-350, The Rand Corporation, Santa Monica, USA, 1952

[20] S. R. Valluri, “A unified engineering theory of high stress level fatigue”, Aerospace Engineering, Vol. 20, No. 10, pp. 18-19, 1961

[21] T. Bui-Quoc, "Cumulative damage with interaction effect due to fatigue under torsion loading", Experimental Mechanics, Vol. 22, No. 5, pp. 180-187, 1982

[22] J. Lemaitre, J. L. Chahoche, “Aspect phénoménologique de la rupture par endommagement”, Journal de Mécanique Appliquée, Vol. 2, No. 3, pp. 317-365, 1978

[23] J. Lemaitre, A. Plumtree, "Application of damage concept to predict creep-fatigue failures”, Trans. ASME, J. Eng. Mater. Technol., Vol. 101, pp. 284-292, 1979

[24] G. Mesmacque, S. Garcia, A. Amrouche, C. Rubio-Gonzalez, "Sequential law in multiaxial fatigue, a new damage indicator", International Journal of Fatigue, Vol. 27, No. 4, pp. 461-467, 2005

[25] A. Aid, Z. Semari, A. Amrouche, G. Mesmacque, M. Benguediab, "Nonlinear damage cumulative model in bloks loading conditions. Application for GS61 spheroïdal graphite cast-iron loaded by torsion and plane bending", Journal of Theoretical znd Applied Mechanics, Vol. 38, No. 4, pp. 101-112, 2008

[26] Aid, A. Amrouche, A. Bachir, B.A. and Benguediab, M, "Fatigue life prediction under variable loading based on a new damage model". Materials \& Design., 32(1),183-191, 2011

[27] A. Aid, M. Bendouba, L. Aminallah, A. Amrouche, N. Benseddiq, M. Benguediab, "An equivalent stress process for fatigue life estimation under multiaxial loadings based a new non linear damage model", Materials Science and Engineering: A, Vol. 538, No. 15, pp. 20-27, 2012

[28] C. Amzallag, J. P. Gerey, J. L. Robert, J. Bahuaud, "Standardization of the rainflow counting method for fatigue analysis", International Journal of Fatigue, Vol. 16, No. 4, pp. 287-93, 1994

[29] ASTM E739-91, Annual book of ASTM standards 03.01, Philadelphia, pp. 614-620, 1998

[30] A. Conle, T. Topper, "Fatigue service histories: techniques for data collection and history regeneration", SAE Technical Paper 820093, Society of Automotive Engineers, 1983

[31] F. E. Richart Jr, N. M. Newmark, "A hypothesis for the determination of cumulative damage in fatigue", Proc. American Society for Testing and Materials, Vol. 48, pp. 767-800, 1948

[32] J.B. Commerce, "The effect of overstress in fatigue on the endurance life of steel", Proc. American Society for Testing and Materials, Vol. 45, pp. 532-541, 1945

[33] A. Aid, J. Chalet, A. Amrouche, G. Mesmacque, M. Benguediab, “A new damage indicator: from blocks loading to random loading", Fatigue Design Conf., Paris, France, November, 2005

[34] O. Buxbaum, "Random load analysis as a link between operational stress measurement and fatigue life assessment. Service fatigue loads monitoring, simulation, and analysis", American Society for Testing and Materials, Vol. 671, pp. 5-20, 1979

[35] N. E. Dowling, "A Review of Fatigue Life Prediction Methods", SAE Technical Paper Series, No. 871966, Passenger Car Meeting and Exposition, Dearborn, Michigan, USA, October, 1987

[36] S. Kocanda, Fatigue failure of metals (fatigue and fracture), Sijthoff \& Noordhoff International, 1978

[37] E. Macha, A. Nieslony, "Random multiaxial fatigue loading", in: Advances in Fatigue, Fracture and Damage Assessment of Materials, Chapter Eight, WIT Press, pp. 213-242, 2005

[38] C. Lalanne, Mechanical Vibration and Shock. Vol. 4: Fatigue Damage, Hermes Penton Science, 2002

[39] L. M. Kachanov, "Rupture time under creep conditions", International Journal of Fracture, Vol. 97, pp. 11-18, 1999

[40] Y. N. Rabotnov, Creep Problems in Structural Members, North-Holland, Amsterdam, 1969

[41] A. Aid, Cumul d'endommagement en fatigue multiaxiale sous sollicitations variables, $\mathrm{PhD}$ Thesis, Universitè de Sidi-Bel Abbes, Algérie, 2006
[42] X. Pitoiset, Méthodes spectrales pour une analyse en fatigue des structures métalliques sous chargements aléatoires multiaxiaux. $\mathrm{PhD}$ Thesis, Université Libres de Bruxelles, 2001

[43] J. D. Clothiaux, N. E. Dowling, "Verification of rain-flow reconstructions of a variable amplitude load history", NASA Contractor Report 189670, Virginia Polytechnic Institute and State University Blacksburg, VA, 1992 